\title{
Effect Of Closed Wound Care Protocol On Nurses.Practices And
} Patients Wound Healing

\author{
M.Sc.Manal Tharwat AbouZaid, Dr. Labiba Abd El-Kader Mohamed, Dr.Mossad \\ Mahmud Morshed, Assistant. Dr. Eman Saleh Shahin, Assistant. Dr. Amal Bakr \\ Abo-El-Ata \\ M.Sc .Medical Surgical Nursing, Faculty of Nursing, Ain Shams University egypt. \\ Professor of Medical-Surgical Nursing, Faculty of Nursing, Caire University, Egypt; \\ Professor of Surgery, Faculty of Medicine - Mansoura University, Egypt; Assistant \\ Professor of \\ Medical Surgical Nursing,Faculty of Nursing - Port Said University, Egypt assistant \\ Professor Of Medical Surgical Nursing, Faculty Of Nursing - \\ Port Said Universityegypt
}

\begin{abstract}
Background: care of wounds is a dynamic, complex process and requires specific knowledge of the nursing team, comprising professionals who will develop this care both in prevention and in the specific treatment. This study aimed to assess nurses' practice regarding closed wound care in the surgical unit, and evaluate the effect of a wound care protocol on nurses' practice in, and assess patients' wound healing pre- and post-applying wound care protocol in at two hospital Mansoura University and emergency hospitals. The study sample includes two groups first group, consisted of 55 nurses from the two hospitals, and second group consist 207 patients with closed wound. The sample of nurses received a suggested protocol regarding wound care. Data collection was accomplished utilizing three tools; Astructured interview for the nurses, wound care observational checklist, andBraden scale, wound assessment tool. Data was collected from both nurses and patients three times; one time before implementing the wound care protocol, and a second time after its implementation and third one after 12 week's follow up. The result of this study revealed a statistically significant improvement in nurses' practice regarding wound care after implementing wound care protocol with (P-value $=0.014$ and 0.000 respectively). Additionally, wound degeneration decreased in post-protocol implementation and during follow-up. The wound regeneration significantly improved with $(\mathrm{P}$-value $=0.000)$ after implementing the wound care protocol. Conclusion: the study concluded presence of an improvement in nurses' practice after implementing the wound care protocol. Also, the wound healing improved significantly. Recommendations: nurses' practice about surgical wound care and infection control in general needs to be updated, through in-service training protocol. The hospital should have policies regarding infection control measures, to be reviewed periodically.
\end{abstract}

Key words: Closed Surgical Wounds, Patients, Wound Regeneration, WOund Degeneration, Assess, Complications, Braden Scale 


\section{INTRODUCTION}

Surgical site infections (SSI) are infections that occur at or near surgical incisions within 30 days of operation, or after 1 year if an implant was placed. SSIs are the $3^{\text {rd }}$ commonly reported infections, accounting for 10 to $40 \%$ of all nosocomial infections. Globally, SSI rates have been found to range from 2.5 to $41.9 \%$.In Western countries, 2 to $5 \%$ of the patients undergoing clean surgeries, and up to $20 \%$ of those undergoing intra-abdominal surgeries will develop SSIs. In Africa, SSIs were the leading causes of infections in hospitals (pooled cumulative incidence of 5.6 per 100 surgical procedures) (Zambudio et al., 2014).

A wound dressing is regarded as a way of protecting the wound from desiccation and external contamination, in addition to reducing pain, absorbing wound drainage and promoting epithelialization (Anderson, 2014).

Despite the availability of many advanced dressings, split-thickness skin graft donor sites are often treated with antiquated methods, which results in painful, unpredictable and potentially-delayed postoperative wound healing (Dawodu, 2014).

Wound assessment is a vital and dynamic process that can help to ensure that patients receive the most appropriate evidence-based interventions available. Accurate wound assessment is essential to the appropriate and realistic planning of goals and interventions for patients with wounds. However, the assessment process has many components that must be systematically considered (Anderson, 2014).

Initially all wounds can be described as acute and are anticipated to progress through a normal wound-healing (Bates-Jensen, 2011).

Wound healing is a complex and dynamic process, with the wound environment changing with the shifting health status of an individual. Knowledge of the physiology of the normal wound healing trajectory through the phases of homeostasis, inflammation, granulation, and maturation, provides a framework for understanding the basic principles of wound healing. Through this understanding, the healthcare professional can develop the skills required to care for a wound and the patient can be helped properly (Sussman\&Jensen, 2016).

It was reported that the normal mammalian response to a break in cutaneous integrity occurs in three overlapping, but biologically distinct, phases. Following the 
initial injury, there is an initial inflammatory phase, the purpose of which is to remove devitalized tissue and prevent invasive infection. Next, there is a proliferative phase during which the balance between scar formation and tissue regeneration occurs. Usually, scar formation predominates, although in fetal wound healing, an impressive amount of regeneration is possible Finally, the longest and least understood phase of wound healing occurs, the remodeling phase, the purpose of which is to maximize the strength and structural integrity of the wound (Dolly, 2013).

protocols and recommendations regarding postoperative dressing practice have been provided to healthcare workers in the United Kingdom. (Rodriguez et al. 2015), recommended that at the end of surgical operations, incisions anticipated to heal by primary intention should be covered by a film membrane with or without a central absorbent. Currently, postoperative dressing practice comprises the use of vaporpermeable film dressings, as those suggested by (Robenson et al. 2016). Although there have been significant advances in the operative techniques and a better understanding of the pathogenesis of wound infection, postoperative wound infection continues to be a major source of morbidity and mortality for patients undergoing operative procedures

\section{Significance of the study:}

Prediction through accurate assessment and prevention of wound complications using appropriate measures is one of the most important goals of nursing care. However, for patients who have already developed wound-related complications, timely intervention can reduce morbidity and mortality rates. The concerted effort of nurses, doctors, and other healthcare providers is necessary for optimal outcomes. As a result, a nursing care clinical practice protocol should be developed to assist such individuals in the prevention and treatment of wound complications, which is a challenge in the care of patients.

\section{THE AIM OF STUDY :}

was to evaluate the effect of Closed Wound care protocol on nurses', practice and healing. This aim was achieved through:

- Assess nurses' practice, open wound care in the surgical unit.

- Design a closed wound care protocol for nurses in the surgical unit

- Implement protocol of closed wound care in the surgical unit 
•Evaluate Patients' wound healing in the surgical unit, pre- and post-applying the closed wound care protocol.

\section{Research hypotheses:}

- The level of nurses' practice regarding closed wound care will be increased significantly after implementing the wound care protocol,and

The patients' wound healing will be improved more than before implementing the wound care protocol.

\section{SUBJECT AND METHODS:}

A quasi-experimental research designed was used in the current study.

\section{The study sample:}

A convenient sample of two groups; nurses and patients, was used in the current study:

Group 1: Convienent sample of all nurses working at the general surgical unit who accepted to participate in the study (55 nurses).

Group 2: All patients admitted to the study settings during the time of data collection (6 months) were invited to participate in the study (206 with closed ones).

\section{Inclusion criteria for patients:}

- Adults of both sexes admitted to the surgical unit.

- Patients with closed wounds (traumatic and non- traumatic)(e.g., patients with appendisititis, cholesisitites, etc).

- Admitted to emergency operations (traumatic and non-traumatic patients).

\section{Exclusion criteria for patients:}

Patients with burns, and those undergoing orthopedic surgeries

\section{Tool of data collection:}

\section{Tool I: A structured interview questionnaire}

A structured interview was developed by the researcher to assess: Demographic

Characteristics of nurses e.g. age, marital status, educational level, years of experience, previous training on wound care.

TOOL II: Wound care observational checklist: 
It was adopted from (Andrews \&Boyle. 2014 Estes. 2015), was modified by the researcher.This tool measured the practice of nurses and how they demonstrated the wound dressing, it contained 41 steps.

\section{Scoring system:}

The nurses were observed while performing wound care and 41 items related to their practices were covered. The nurses were rated in accordance to whether they performed these practices or not. A score of "1" was given for done and a score of "0" was given for not done. The total practice score was classified into the following two categories:

- A total practice score $\geq 60 \%$ was considered satisfactory.

- A total practice score $<60 \%$ was considered unsatisfactory.

\section{Reliability of the tools:}

Reliability of practice checklist of nurses Cronbach's Alpha $=0.799$ ).

TOOL III: Wound healing assessment: It included.

Closed-wound healing assessment, adapted from Braden's wound assessment scale (Braden \&Bergstrom, 2015). It was composed of 13 items these items were: wound site, size, wound bed, drainage, colour, odour, undermining, surrounding tissue, oedema, stoma, wound status, wound care, and satisfaction of patient.

\section{Scoring system:}

The closed wound's status was assessed by adding together a 16-items' scores. The wound condition was classified into two categories, namely poor wound healing (score: 1 to 13) and good wound healing (score: 14 to 60). From braden sheet listed.

\section{Reliability statistics:}

Braden's wound assessment scale (Cronbach's Alpha $=0.633)$.

. TOOL (IV): Protocol for wound care. Its development included the following phases:

Phase 1: Developing nursing protocol regarding closed wound care after reviewing relevant literature: (Chou \&Conifer, 2012; Canadian Association of Wound Care, 2014; Australian Medicines Handbook, 2015; Lippincott. 2015). Taylor, et al., 
2017; this tool contained the following steps; how to assess the wound, how to perform a physical examination for the patient, performing wound care, and wound dressing.

Phase 2: Providing an opinionnaire of expertise (for nurses and physicians) regarding the developed protocol of closed wound care.

Phase 3: Constructing the final form of the developed wound care protocol based on the results of the opinionnaire of expertise and the relevant literature.

\section{Methods of data collection:}

This study was covered in four phases:-

1-Validity of tool:-. 9 experts were reviewing the content validity of the tool from surgical doctors and medical surgical nursing professor in the field after translation of the tool from English to Arabic language.

\section{2- Reliability:}

Structured interview regarding nurses' knowledge (Cronbach's Alpha $=0.788$ ).

Bates-Jensen scale (Cronbach's Alpha $=0.789$ ).

\section{3- Ethical considerations:}

- An informed consent was obtained from the patients and nurses to participate in the study after explaining its aim.

- The researcher assured the study sample of maintaining the anonymity and confidentiality of their data.

- $\quad$ Patients and nurse were informed that they could withdraw from the study at any time.

4- Pilot study: - Pilot study was carried out after the development of the tools on $10 \%$ of the nurses to test( 6 nurse ) applicability of the tools then necessary modification were done according to the results of pilot study and expertise opinions. The purpose of pilot study was: To test the applicability and feasibility of the study tools.

To estimate any need for addition or omission in the tool, and time needed to fill in the tool. Otherwise, these nurses were then excluded from the sample of research work to assure the stability of answers

5- Field work: data were collected from two hospitals at Elmansoura university hospitaland Emergency hospital in Elmansoura City at four months from September 2015 until march 2016 for three days weekly mainly Saturday, Sunday and Thursday in 
the morning shift, each week according to time available to nurses . Each nurse takes time approximately between 30-45 minutes to fill a questionnaire.

\section{Statistical analysis:}

- The collected data were coded and analysed using the Statistical Package for Social Sciences (SPSS version 20).

- Tabulated frequencies and percentages were calculated.

- The level of significance selected for this study was P-value $\leq 0.05$.

\section{RESULTS:}

Table (1): shows that most of the studied nurses at Mansoura university and emergency hospitals were females.Moreover,the ages of more than half of the nurses at Mansoura hospital ranged from 20 to less than35years, while at Mansoura emergency hospital, the ages of $25.8 \%$ of the nurses were from 35 to 40 years.Regarding the years of experience, it was found that more than half of the nurses at Mansoura university hospital at Mansoura emergency hospital had an experience of 10 years or more. Moreover, with respect to the years of experience in surgical units, more thanhalf of the nurses at Mansoura university hospital, at Mansoura emergency hospital, had 5 to less than 10 years of experience.Concerning the nurses' educational level,most of nurses at Mansoura emergency hospital and at Mansoura university hospital, had secondary education.

Table (2A): shows that regarding the common steps of wound care practice, none of the studied nurses performed any of the following steps pre-protocol.: (review the medical orders for wound care, perform hand hygiene and put on PPE, identify the patient, close curtains around the bed and close room's door, if possible (keep patient's privacy, explain the procedure to the patient, and assist the patient to a comfortable position that provides easy access to the wound area) .However, these steps improved significantly immediately post-protocol., and after 12 weeks

Table (2B): shows that during the wound dressing procedure, none of the studied nurses performed the following steps pre-protocol.: (use awaterproof pad under the wound site, and check the position of drains, tubes, or other adjuncts before removing the dressing). However, post-protocol., all the nurses answered correctly $(85.5 \%$ and $100 \%$, respectively). Furthermore, regarding the steps of: after removing the dressing, note the following: amount, type, colour, and odour of the dressings, and assessing the 
presence of pain, only $21.8 \%$ and $18.2 \%$, respectively of the study sample correctly mentioned these steps pre-protocol., however, these percentages improved to $74.5 \%$ at the immediate post-protocol. Phase, and to $74.5 \%$ and $83.6 \%$, respectively after 12 weeks post-protocol.

Table (2C): shows that the least percentage of the studied nurses reported correct answers in the following steps pre-protocol.: after securing the dressing, label dressing with date and time (20\%), and note and document any abnormal observations (27.3\%). However, the nurses' responses improved post-protocol. (78.2\% and $92.7 \%$, respectively).

Table (3): shows that pre-protocol., most of the studied nurses in Mansoura university hospital had unsatisfactory practice, while more than half of those in Mansoura emergency hospital had satisfactory practice. However, in the immediate post-protocol. Phase, the studied nurses in Mansoura university hospital and emergency hospital had satisfactory practice (95.8\% and $80.6 \%$, respectively). Furthermore, after 12 weeks post-protocol., the studied nurses at Mansoura University and emergency hospitals showed satisfactory practice ( $70.8 \%$ and $64.5 \%$, respectively).

Table (4): shows that (31.4\%) of the studied patients, were ranged in 25-30 years oldregarding to genders, $70.5 \%$, were males.Regarding the patients' educational level, $42.5 \%$ of the studied patients. were illiterate, concerning the occupation of the studied patients, $65.7 \%$ Were working. Also, from the studied patients, $65.7 \%$ lived in rural

- Table (5): shows that (52.2\%) of studied patients with closed wound according to wound healing scale in pre-protocol. have wound regeneration and in immediate postprotocol. has $(94.2 \%)$ have wound regeneration and in follow up after 12 weeks have $(87.9 \%)$ in wound regeneration

Table (6): shows that less than one fourth of closed wound patient had degeneration in pre protocol and had $(3.9 \%),(7.2 \%)$ of moderate wound degeneration in post immediate and post 12 weeks post protocol.had of sever wound degeneration

Table (7): shows the relation between socio-demographic data and wound healing in patients with closed wounds. It illustrated that $83.8 \%$ of the studied patients with less than 50 years of age had poor skin healing pre-protocol., while $67.7 \%$, immediately post-protocol., and $75.3 \%$ after 12 weeks post-protocol., had healthy skin.Moreover, it was described that $72.7 \%$ of the studied male patients pre-protocol. showed poor 
healing, while $66.7 \%$ immediately post-protocol., and during follow-up patientsshowed healthy skin.

Table (1): Scio-demographic characteristics of the studied nurses $(\mathrm{N}=55)$.

\begin{tabular}{|c|c|c|c|c|c|c|}
\hline \multirow{3}{*}{ Bio-damographic characteristics } & \multicolumn{4}{|c|}{ Hospital's name } & \multirow{2}{*}{\multicolumn{2}{|c|}{ Total $(\mathrm{N}=55)$}} \\
\hline & \multicolumn{2}{|c|}{$\begin{array}{c}\text { Mans oura university hospital(n= } \\
\text { 24) }\end{array}$} & \multicolumn{2}{|c|}{$\begin{array}{l}\text { Mansoura emergency hospital(n= } \\
\text { 31) }\end{array}$} & & \\
\hline & No. & $\%$ & No. & $\%$ & No. & $\%$ \\
\hline \multicolumn{7}{|l|}{ 1-Gender: } \\
\hline Mala. & 1 & 4.2 & 3 & 9.7 & 4 & 7.3 \\
\hline Female. & 23 & 95.8 & 28 & 90.3 & 51 & 92.7 \\
\hline \multicolumn{7}{|l|}{ 2-Age (years): } \\
\hline $20<25$ & 7 & 29.2 & 6 & 19.4 & 13 & 23.6 \\
\hline $25<30$ & 5 & 20.8 & 5 & 16.1 & 10 & 18.2 \\
\hline $30<35$ & 7 & 29.2 & 8 & 25.8 & 15 & 27.3 \\
\hline $35<40$ & 1 & 4.2 & 9 & 29 & 10 & 18.2 \\
\hline 40 and more & 4 & 16.7 & 3 & 9.7 & 7 & 12.7 \\
\hline Mean = SD & \multicolumn{6}{|l|}{$30.69 \pm 7.2$} \\
\hline \multicolumn{7}{|l|}{ 3- Years of experience: } \\
\hline Less than 5 years. & 5 & 20.8 & 9 & 29 & 14 & 25.5 \\
\hline 5 to less than 10 . & 5 & 20.8 & 3 & 9.7 & 8 & 14.5 \\
\hline 10 years and more. & 14 & 58.3 & 19 & 61.3 & 33 & 60 \\
\hline $\begin{array}{l}\text { Mean }=\text { SD } \\
\text { 4- Years of experience at surgery } \\
\text { unit: }\end{array}$ & \multicolumn{6}{|l|}{$12.2 \pm 7.534$} \\
\hline 185 & 10 & 41.7 & 10 & 32.3 & 20 & 36.4 \\
\hline $5<10$ & 7 & 29.2 & 12 & 38.7 & 19 & 34.5 \\
\hline $10+$ & 7 & 29.2 & 9 & 29 & 16 & 29.1 \\
\hline Mean \pm SD & \multicolumn{6}{|l|}{$8.25 \pm 5.552$} \\
\hline \multicolumn{7}{|l|}{ 5-Educational level: } \\
\hline Secondary nursing education. & 18 & 75 & 24 & 77.4 & 42 & 76.4 \\
\hline Technical nursing institution. & 6 & 25 & 7 & 22.6 & 13 & 23.6 \\
\hline
\end{tabular}

Furthermore, $45.5 \%$ of the studied illiterate patients pre-protocol. had poor healing,while immediately post-protocol and during follow-up post-protocol who could read and write had healthy skin and also. according to the place of residence patientswho lived in rural areas complained of poor healing, while patients live in urban residence had healthy skin. 
Table (2A): Distribution of wound care practice Score among the studied nurses at Mansoura University and emergency hospitals:

\begin{tabular}{|c|c|c|c|c|c|c|c|c|c|c|c|c|}
\hline \multirow{3}{*}{ Wound carle practice } & \multicolumn{4}{|c|}{ Pre-protocol. } & \multicolumn{4}{|c|}{ Immediate post-protocol. } & \multicolumn{4}{|c|}{12 weeks post-protocol. } \\
\hline & \multicolumn{2}{|c|}{$\mathrm{Y}_{\mathrm{es}}$} & \multicolumn{2}{|l|}{ No } & \multicolumn{2}{|c|}{ Yes } & \multicolumn{2}{|c|}{$\mathbb{N}_{0}$} & \multicolumn{2}{|c|}{ Yes } & \multicolumn{2}{|l|}{$\mathrm{N}_{0}$} \\
\hline & No. & $\%$ & No. & $\%$ & No. & $\%$ & No. & $\%$ & No. & $\%$ & No. & $\%$ \\
\hline \multicolumn{13}{|l|}{ Common staps: } \\
\hline 1. Revien the madical orders for wound care. & 0 & 0 & 55 & 100 & 55 & 100 & 0 & 0 & 55 & 100 & 0 & 0 \\
\hline $\begin{array}{l}\text { 2. Gather the necessary supplies and bring it to the } \\
\text { bedside stand or over the bed table. }\end{array}$ & 36 & 65.5 & 19 & 34.5 & 45 & 818 & 10 & 182 & 44 & 80 & 11 & 20 \\
\hline $\begin{array}{l}\text { 3. Pefform hand hygiene and put on PPE (personal } \\
\text { protective equipment). }\end{array}$ & 0 & 0 & 55 & 100 & 55 & 100 & 0 & 0 & 55 & 100 & 0 & 0 \\
\hline 4. Identify the patient. & 0 & 0 & 55 & 100 & 55 & 100 & 0 & 0 & 55 & 100 & 0 & 0 \\
\hline $\begin{array}{l}\text { 5. Close curtains around tha bed and dose room's } \\
\text { door, if possibla (keap patient's privacy). }\end{array}$ & 0 & 0 & 55 & 100 & 47 & 855 & 8 & 14.5 & 44 & 80 & 11 & 20 \\
\hline 6. Explain the procedure to the patient. & 0 & 0 & 55 & 100 & 46 & 836 & 9 & 164 & 46 & 836 & 9 & 16.4 \\
\hline $\begin{array}{l}\text { 7. Assass tha patients nasds for phamacological } \\
\text { pair- ralief interventions or analgesic medications } \\
\text { before wound care. }\end{array}$ & 8 & 145 & 47 & 855 & 40 & 72.7 & 15 & 273 & 40 & 72.7 & 15 & 27.3 \\
\hline $\begin{array}{l}\text { 8. Placa a wasta recaptacla containger or bag at a } \\
\text { convenient location for usa during the procadure. }\end{array}$ & 55 & 100 & 0 & 0 & 55 & 100 & 0 & 0 & 46 & 836 & 9 & 16.4 \\
\hline $\begin{array}{l}\text { 9. Adjust bed to a comfortable working heieght, } \\
\text { usually at the waist lavel. }\end{array}$ & 7 & 12.7 & 47 & 873 & 44 & 80 & 11 & 20 & 44 & 80 & 11 & 20 \\
\hline $\begin{array}{l}\text { 10.Assist the patient to a comfortabla position that } \\
\text { prowides asy access to the wound area. }\end{array}$ & 0 & 0 & 55 & 100 & 43 & 782 & 12 & 218 & 46 & 836 & 9 & 16.4 \\
\hline
\end{tabular}


Table (2B): Distribution of wound care practice among the studied nurses at Mansoura university and Emergency hospitals:

\begin{tabular}{|c|c|c|c|c|c|c|c|c|c|c|c|c|}
\hline \multirow{3}{*}{ Wound care pratice } & \multicolumn{4}{|c|}{ Preprotocol. } & \multicolumn{4}{|c|}{ Immediate post-protocol. } & \multicolumn{4}{|c|}{12 rusel post-protorol. } \\
\hline & \multicolumn{2}{|c|}{ Yes } & \multicolumn{2}{|l|}{ No } & \multicolumn{2}{|l|}{ Yes } & \multicolumn{2}{|l|}{ No } & \multicolumn{2}{|l|}{ Yes } & \multicolumn{2}{|c|}{ No } \\
\hline & $\begin{array}{l}\mathbb{N} \\
0 .\end{array}$ & $\%$ & No. & $\%$ & No. & $\%$ & No. & $\%$ & No. & $\%$ & No. & $\%$ \\
\hline \multicolumn{13}{|l|}{ Wound dressing procedure: } \\
\hline 11. Ues awaterproof pad under the wound site. & 0 & 0 & 55 & 100 & 47 & 85.5 & 8 & 14.5 & 47 & 85.5 & 8 & 14.5 \\
\hline $\begin{array}{l}\text { 12. Chat: the position of drains, tubs, or other } \\
\text { adjunts before removing the dressing. }\end{array}$ & 0 & 0 & 55 & 100 & 55 & 100 & 0 & 0 & 55 & 100 & 0 & 0 \\
\hline $\begin{array}{l}\text { 13. Put on clean, disposable gloves and lowe tape on } \\
\text { the old drasinge. }\end{array}$ & 55 & 100 & 0 & 0 & 55 & 100 & 0 & 0 & 55 & 100 & 0 & 0 \\
\hline 14. Crefilly remove the soilad drasings. & 39 & 70.9 & 16 & 29.1 & 47 & 85.5 & 8 & 14.5 & 47 & 85.5 & 8 & 14.5 \\
\hline $\begin{array}{l}\text { 15. If any part of the dressing sticks to the underlying } \\
\text { akin: use small anounts of sterile saline to halp } \\
\text { loosen and remove it. }\end{array}$ & 40 & 72.7 & 15 & 27.3 & 47 & 85.5 & 8 & 14.5 & 46 & 83.6 & 9 & 16.4 \\
\hline $\begin{array}{l}\text { 16. After removing the dressing, note the following: } \\
\text { anount, type, colour, and odvur of the dressings. }\end{array}$ & 12 & 21.8 & 43 & 78.2 & 41 & 74.5 & 14 & 25.5 & 41 & 74.5 & 14 & 25.5 \\
\hline $\begin{array}{l}\text { 17. Place soiled dresings in the appropriate waste } \\
\text { receptacle. }\end{array}$ & 55 & 100 & 0 & 0 & 55 & 100 & 0 & 0 & 55 & 100 & 0 & 0 \\
\hline $\begin{array}{l}\text { 18. Remove glowes and dispose of them in an } \\
\text { appropriate waste recoptacle. }\end{array}$ & 55 & 100 & 0 & 0 & 55 & 100 & 0 & 0 & 55 & 100 & 0 & 0 \\
\hline $\begin{array}{l}\text { 19. Inspact the wound site for size, apparance, and } \\
\text { drainage. }\end{array}$ & 27 & 49.1 & 28 & 50.9 & 33 & 60 & 2 & 40 & 33 & 60 & 22 & 40 \\
\hline 20. Asuss the presence of pain. & 10 & 18.2 & 45 & 81.8 & 41 & 74.5 & 14 & 25.5 & 46 & 83.6 & 9 & 16.4 \\
\hline $\begin{array}{l}\text { 21. Chat: the status of sutures, alhasive closure } \\
\text { strips, staplas, and drains or tubas, if present. }\end{array}$ & 55 & 100 & 0 & 0 & 55 & 100 & 0 & 0 & 55 & 100 & 0 & 0 \\
\hline $\begin{array}{l}\text { 2. Using stsile techniqus, prepre a sterile work } \\
\text { area and open the neadsd suppliss. }\end{array}$ & 25 & 45.5 & 30 & 54.5 & 38 & 69.1 & 17 & 30.9 & 38 & 69.1 & 17 & 30.9 \\
\hline 23. Open the sterile clesning solution. & 55 & 100 & 0 & 0 & 55 & 100 & 0 & 0 & 55 & 100 & 0 & 0 \\
\hline \multicolumn{13}{|l|}{$\begin{array}{l}\text { Depending on the anount of cleaning neaded, the } \\
\text { solution might bepoured diretly over gauze sponges } \\
\text { wer a container for mall cleaning jobs. }\end{array}$} \\
\hline 24. Put on sterile gloves. & 24 & 43.6 & 31 & 56.4 & 55 & 100 & 0 & 0 & 55 & 100 & 0 & 0 \\
\hline $\begin{array}{l}\text { 25. Clean the wound from top to bottom and from } \\
\text { the cantre to the outside. }\end{array}$ & 55 & 100 & 0 & 0 & 55 & 100 & 0 & 0 & 55 & 100 & 0 & 0 \\
\hline $\begin{array}{l}\text { 26. Following this pattem, use new gaune for each } \\
\text { wipe. }\end{array}$ & 33 & 60 & 22 & 40 & 48 & 87.3 & 7 & 12.7 & 48 & 87.3 & 7 & 12.7 \\
\hline 27. Place the used gauze in the waste receptacle. & 55 & 100 & 0 & 0 & 55 & 100 & 0 & 0 & 55 & 100 & 0 & 0 \\
\hline $\begin{array}{l}\text { 28. One the wound is cleand, dry the area using a } \\
\text { gauze sponge in the same manner. }\end{array}$ & 55 & 100 & 0 & 0 & 55 & 100 & 0 & 0 & 46 & 83.6 & 9 & 16.4 \\
\hline $\begin{array}{l}\text { 29. Apply ointment or perform other trestments, as } \\
\text { praccibsi. }\end{array}$ & 55 & 100 & 0 & 0 & 55 & 100 & 0 & 0 & 55 & 100 & 0 & 0 \\
\hline $\begin{array}{l}\text { 30. If a drain is in use at the wound location, clean } \\
\text { around the drain. }\end{array}$ & 55 & 100 & 0 & 0 & 55 & 100 & 0 & 0 & 46 & 83.6 & 9 & 16.4 \\
\hline $\begin{array}{l}\text { 31. Apply a layer of dry, sterile dressing over the } \\
\text { wound with forcops to spply the dressing. }\end{array}$ & 55 & 100 & 0 & 0 & 55 & 100 & 0 & 0 & 55 & 100 & 0 & 0 \\
\hline $\begin{array}{l}\text { 32. Place the second layer of gauze over the wound } \\
\text { site. }\end{array}$ & 55 & 100 & 0 & 0 & 55 & 100 & 0 & 0 & 44 & 80 & 11 & 20 \\
\hline
\end{tabular}


Table (2C): Distribution of wound care practice among the studied nurses at Mansoura university and emergency hospitals:

\begin{tabular}{|c|c|c|c|c|c|c|c|c|c|c|c|c|}
\hline \multirow[t]{3}{*}{ Wound care practica } & \multicolumn{4}{|c|}{ Pre-protocol. } & \multicolumn{4}{|c|}{$\begin{array}{l}\text { Immediate post- } \\
\text { protocol. }\end{array}$} & \multicolumn{4}{|c|}{12 weeks post-protocol. } \\
\hline & \multicolumn{2}{|l|}{ Yes } & \multicolumn{2}{|l|}{ No } & \multicolumn{2}{|c|}{ Yes } & \multicolumn{2}{|l|}{ No } & \multicolumn{2}{|c|}{ Yes } & \multicolumn{2}{|l|}{$\mathbb{N}_{0}$} \\
\hline & No. & $\%$ & No & $\%$ & No & $\%$ & No & $\%$ & No. & $\%$ & No. & $\%$ \\
\hline \multicolumn{13}{|l|}{ Post procedure care: } \\
\hline 33. Remove gloves. & 55 & 100 & 0 & 0 & 55 & $\begin{array}{l}10 \\
0\end{array}$ & 0 & 0 & 55 & 100 & 0 & 0 \\
\hline $\begin{array}{l}\text { 34. Apply tape or roller gauza to secure the } \\
\text { dressings }\end{array}$ & 55 & 100 & 0 & 0 & 55 & $\begin{array}{l}10 \\
0\end{array}$ & 0 & 0 & 46 & 83.6 & 9 & 16.4 \\
\hline $\begin{array}{l}\text { 35. After securing the dressing, label dressing } \\
\text { with date and time. }\end{array}$ & 11 & 20 & 44 & 80 & 43 & $\begin{array}{l}78 . \\
2\end{array}$ & 12 & $\begin{array}{l}21 . \\
8\end{array}$ & 43 & 78.2 & 12 & 21.8 \\
\hline 36. Remove all ramaining equipment. & 55 & 100 & 0 & 0 & 55 & $\begin{array}{l}10 \\
0\end{array}$ & 0 & 0 & 55 & 100 & 0 & 0 \\
\hline $\begin{array}{l}\text { 37. Place the patient in a comfortable position, } \\
\text { with side rails up and bed in the lowest } \\
\text { position. }\end{array}$ & 0 & 0 & 55 & $\begin{array}{l}10 \\
0\end{array}$ & 55 & $\begin{array}{l}10 \\
0\end{array}$ & 0 & 0 & 46 & 83.6 & 9 & 16.4 \\
\hline 38. Remove PPE, if used. & 55 & 100 & 0 & 0 & 55 & $\begin{array}{l}10 \\
0\end{array}$ & 0 & 0 & 44 & 80 & 11 & 20 \\
\hline 39. Peffom hand hygiene. & 15 & 27.3 & 40 & $\begin{array}{l}72 . \\
7\end{array}$ & 48 & $\begin{array}{l}87 . \\
3\end{array}$ & 7 & $\begin{array}{l}12 \\
7\end{array}$ & 48 & 87.3 & 7 & 12.7 \\
\hline 40. Check all wound dressings avery shift. & 0 & 0 & 55 & $\begin{array}{l}10 \\
0\end{array}$ & 45 & $\begin{array}{l}81 . \\
8\end{array}$ & 10 & $\begin{array}{l}18 . \\
2\end{array}$ & 45 & 81.8 & 10 & 18.2 \\
\hline $\begin{array}{l}\text { 41. Note and document any abnomal } \\
\text { observations. }\end{array}$ & 15 & 27.3 & 40 & $\begin{array}{l}72 . \\
7\end{array}$ & 51 & $\begin{array}{l}92 . \\
7\end{array}$ & 4 & 7.3 & 51 & 92.7 & 4 & 7.3 \\
\hline
\end{tabular}


Table (3): Wound care practice score among studied nurses at El-Mansoura university and emergency hospitals $(\mathrm{N}=55)$.

\begin{tabular}{|c|c|c|c|c|c|c|c|c|c|c|c|c|c|c|c|c|c|c|c|c|c|}
\hline \multirow{4}{*}{$\begin{array}{c}\text { Total } \\
\text { wound care } \\
\text { practice }\end{array}$} & \multicolumn{7}{|c|}{ Pre-protocol, } & \multicolumn{7}{|c|}{ Immediate post -protocol, } & \multicolumn{7}{|c|}{ l12weels post-protocol. } \\
\hline & \multicolumn{4}{|c|}{ Hospital's name } & \multirow{2}{*}{\multicolumn{2}{|c|}{$\begin{array}{c}\text { Total } \\
(\mathrm{N}=55)\end{array}$}} & \multirow{3}{*}{$\begin{array}{c}\mathrm{X} 2 \mathrm{Te} \\
\text { st } \\
\text { P- } \\
\text { value }\end{array}$} & \multicolumn{4}{|c|}{ Hospital's name } & \multirow{2}{*}{\multicolumn{2}{|c|}{$\begin{array}{r}\text { Total } \\
(\mathrm{N}=55)\end{array}$}} & \multirow{3}{*}{$\begin{array}{c}\mathrm{X} 2 \mathrm{Te} \\
\text { st } \\
\mathrm{P}- \\
\text { value }\end{array}$} & \multicolumn{4}{|c|}{ Hospital's name } & \multirow{2}{*}{\multicolumn{2}{|c|}{$\begin{array}{l}\text { Total } \\
(\mathrm{N}=55)\end{array}$}} & \multirow{3}{*}{$\begin{array}{l}\text { X:Te } \\
\text { st } \\
\text { P- } \\
\text { value }\end{array}$} \\
\hline & \multicolumn{2}{|c|}{\begin{tabular}{|c|} 
El \\
Mansou \\
ra \\
universi \\
ty \\
hospital \\
$(\mathrm{n}=24)$ \\
\end{tabular}} & \multicolumn{2}{|c|}{$\begin{array}{c}\text { El } \\
\text { Mansou } \\
\text { ra } \\
\text { emerge } \\
\text { ncy } \\
\text { hospital } \\
\text { (n=3l) }\end{array}$} & & & & \multicolumn{2}{|c|}{\begin{tabular}{|c|} 
El \\
Mansour \\
$a$ \\
univergit \\
$y$ \\
hospital \\
$(\mathrm{n}=14)$
\end{tabular}} & \multicolumn{2}{|c|}{$\begin{array}{c}\text { El } \\
\text { Mansour } \\
\text { a } \\
\text { emergen } \\
c y \\
\text { hospital } \\
(\mathrm{n}=31)\end{array}$} & & & & \multicolumn{2}{|c|}{\begin{tabular}{|c|} 
El \\
Mansour \\
a \\
univergit \\
$y$ \\
hospital \\
(n=:4)
\end{tabular}} & \multicolumn{2}{|c|}{\begin{tabular}{|c|} 
El \\
Mansour \\
$a$ \\
emergen \\
cy \\
hospital \\
(n=31) \\
\end{tabular}} & & & \\
\hline & $\begin{array}{l}\mathrm{N} \\
0 .\end{array}$ & $\%$ & $\begin{array}{l}\mathrm{N} \\
0 .\end{array}$ & $\%$ & $\begin{array}{l}\mathrm{N} \\
0 .\end{array}$ & $\%$ & & $\begin{array}{l}\mathrm{N} \\
0 .\end{array}$ & $\%$ & $\begin{array}{l}\mathrm{N} \\
0 .\end{array}$ & $\%$ & $\begin{array}{l}\mathrm{N} \\
0\end{array}$ & $\%$ & & $\begin{array}{l}\mathrm{N} \\
0 .\end{array}$ & $\%$ & $\begin{array}{l}\mathrm{N} \\
0 .\end{array}$ & $\%$ & $\begin{array}{l}\mathrm{N} \\
0 .\end{array}$ & $\%$ & \\
\hline $\begin{array}{l}\text { Unsatisfacto } \\
\text { y }\end{array}$ & 20 & $\begin{array}{l}8 \\
3 . \\
3\end{array}$ & $\begin{array}{l}1 \\
2\end{array}$ & $\begin{array}{l}3 \\
8 . \\
7\end{array}$ & $\begin{array}{l}3 \\
2\end{array}$ & $\begin{array}{l}5 \\
8 . \\
2\end{array}$ & $\begin{array}{l}\mathrm{X} 2 \\
(2.74 \\
3)\end{array}$ & 1 & $\begin{array}{l}4 . \\
2\end{array}$ & 6 & $\begin{array}{l}19 \\
.4\end{array}$ & 7 & $\begin{array}{l}1 \\
2 . \\
7\end{array}$ & $\begin{array}{l}\mathrm{X} 2 \\
2.80\end{array}$ & 7 & $\begin{array}{l}2 \\
9 . \\
2\end{array}$ & $\begin{array}{l}1 \\
1\end{array}$ & $\begin{array}{l}3 \\
5 \\
5\end{array}$ & $\frac{1}{8}$ & $\begin{array}{l}3 \\
2 . \\
7\end{array}$ & $\begin{array}{l}\mathrm{X} \\
(3.33\end{array}$ \\
\hline Satisfactory & 4 & $\begin{array}{l}1 \\
6 . \\
7\end{array}$ & $\begin{array}{l}1 \\
9\end{array}$ & $\begin{array}{l}6 \\
1 . \\
3 \\
\end{array}$ & $\begin{array}{l}2 \\
3\end{array}$ & $\begin{array}{l}4 \\
1 . \\
8\end{array}$ & $\begin{array}{l}\mathrm{P} \\
80.00 \\
1\end{array}$ & $\begin{array}{l}2 \\
3\end{array}$ & $\begin{array}{l}9 \\
5 \\
8\end{array}$ & $\begin{array}{l}2 \\
5\end{array}$ & $\begin{array}{c}80 \\
6\end{array}$ & $\begin{array}{l}4 \\
8\end{array}$ & $\begin{array}{l}8 \\
7 . \\
3 \\
\end{array}$ & $\begin{array}{l}\text { y) } \\
\mathrm{P} \\
0.094\end{array}$ & $\begin{array}{l}1 \\
7\end{array}$ & $\begin{array}{l}7 \\
0 . \\
8\end{array}$ & $\begin{array}{l}2 \\
0\end{array}$ & $\begin{array}{l}6 \\
4 . \\
5\end{array}$ & $\begin{array}{l}3 \\
7\end{array}$ & $\begin{array}{l}6 \\
7 . \\
3\end{array}$ & $\begin{array}{l}2) \\
\mathrm{P} \\
0.42\end{array}$ \\
\hline
\end{tabular}

¿Signiffant at P-value $\leq 0.05$

Table (4): Scio-demographic characteristics of the patients with closed wounds. 


\begin{tabular}{|c|c|c|}
\hline \multirow[t]{2}{*}{ Socio-demographic characteristics } & \multicolumn{2}{|c|}{$\begin{array}{l}\text { Closed-wound } \\
(\mathrm{N}=207)\end{array}$} \\
\hline & No. & $\%$ \\
\hline \multicolumn{3}{|l|}{ Age (Years) } \\
\hline $20<25$ & 40 & 19.3 \\
\hline $25<30$ & 65 & 31.4 \\
\hline $30<35$ & 32 & 15.4 \\
\hline $35<40$ & 10 & 4.8 \\
\hline 40 and 50 & 15 & 7.2 \\
\hline More than 50 & 45 & 21.7 \\
\hline Mean \pm SD & \multicolumn{2}{|c|}{$40.1 \pm 14.9$} \\
\hline \multicolumn{3}{|l|}{ Sex } \\
\hline Male & 146 & 70.5 \\
\hline Female & 61 & 29.5 \\
\hline \multicolumn{3}{|l|}{ Marital status } \\
\hline Single & 65 & 31.4 \\
\hline Married & 98 & 47.3 \\
\hline Widowed & 28 & 13.5 \\
\hline Divorced & 16 & 7.7 \\
\hline \multicolumn{3}{|l|}{ Level of education } \\
\hline Illiterate & 88 & 42.5 \\
\hline Primary & 73 & 35.3 \\
\hline Preparatory & 26 & 12.6 \\
\hline Secondary & 16 & 7.7 \\
\hline University & 4 & 1.9 \\
\hline \multicolumn{3}{|l|}{ Occupation } \\
\hline Working & 136 & 65.7 \\
\hline Non-working & 71 & 34.3 \\
\hline \multicolumn{3}{|l|}{ Place of residence } \\
\hline Rural & 136 & 65.7 \\
\hline Urban & 71 & 34.3 \\
\hline
\end{tabular}


Table (5) : Wound Healing based on Modified Braden Wound Assessment Scale among Studied Closed Wound Patients (N=207)

\begin{tabular}{|c|c|c|c|c|c|c|c|}
\hline $\begin{array}{l}\text { Modified Braden } \\
\text { Wound healing score }\end{array}$ & \multicolumn{2}{|c|}{$\begin{array}{l}\text { Pre-protocol } \\
\mathrm{N}(207)\end{array}$} & \multicolumn{2}{|c|}{$\begin{array}{l}\text { Immediate } \\
\text { post protocol } \\
\mathrm{N}(207)\end{array}$} & \multicolumn{2}{|c|}{$\begin{array}{l}\text { Post protocol } \\
12 \text { weeks } \\
\mathrm{N}(207)\end{array}$} & Test P Value \\
\hline & $\mathrm{NO}$ & $\%$ & $\mathrm{NO}$ & $\%$ & $\mathrm{NO}$ & $\%$ & \multirow{3}{*}{$\begin{array}{l}\text { Freidman } \\
\text { test } 13.348 \\
\mathrm{P} \text { value } \\
* 0.000\end{array}$} \\
\hline $\begin{array}{l}\text { Total patients Wound } \\
\text { regeneration }\end{array}$ & 108 & 52.2 & 195 & 94.2 & 182 & 87.9 & \\
\hline $\begin{array}{l}\text { Total patients Wound } \\
\text { degeneration }\end{array}$ & 99 & 47.8 & 12 & 5.79 & 25 & 12 & \\
\hline
\end{tabular}

* Sig: p-value for Freidman test $\leq 0.05$

Table (6): Wound Healing based on Modified Braden degeneration phase among Studied Closed Wound Patients (N=99) 


\begin{tabular}{|l|l|l|l|l|l|l|}
\hline $\begin{array}{l}\text { Modified Braden Wound healing } \\
\text { score }\end{array}$ & $\begin{array}{l}\text { Pre-protocol. N } \\
(99)\end{array}$ & \multicolumn{2}{|l|}{$\begin{array}{l}\text { Immediate post } \\
\text { protocol N (12) }\end{array}$} & \multicolumn{2}{|c|}{$\begin{array}{l}\text { Post protocol } \\
12 \text { weeks N } \\
(25)\end{array}$} \\
\hline $\begin{array}{l}\text { Total patients Wound degeneration } \\
\text { distributions as : }\end{array}$ & NO & $\%$ & NO & $\%$ & NO & $\%$ \\
\hline Mild & 9 & 4.3 & 2 & 0.9 & 5 & 2.4 \\
\hline Moderate & 60 & 28.9 & 8 & 3.9 & 5 & 2.4 \\
\hline Severe (Necrotizing tissue) & 30 & 14.4 & 2 & 0.9 & 15 & 7.2 \\
\hline Total & 99 & 47.8 & 12 & 5.79 & 25 & 12 \\
\hline
\end{tabular}


Table (7): Modified Braden closed wound assessment score among the studied closedwound patients at Mansoura university and emergency hospitals in relation to their socio-demographic characteristics $(\mathrm{N}=207)$.

\begin{tabular}{|c|c|c|c|c|c|c|c|c|c|c|c|c|c|c|c|c|c|c|c|c|c|}
\hline \multirow{5}{*}{$\begin{array}{c}\text { Srip- } \\
\text { demogruptic } \\
\text { characteritiss }\end{array}$} & \multirow{2}{*}{\multicolumn{7}{|c|}{ Prt-protorol }} & \multicolumn{14}{|c|}{ Pot-protorol } \\
\hline & & & & & & & & & & & \multicolumn{4}{|c|}{ Immedate } & \multicolumn{7}{|c|}{ Aftar 12 wats } \\
\hline & \multicolumn{4}{|c|}{$\begin{array}{l}\text { Motfified Bradtn womd } \\
\text { marment } \pi \text { alt }\end{array}$} & \multirow{2}{*}{\multicolumn{2}{|c|}{$\begin{array}{c}\text { Totsl } \\
(\mathrm{N}=207)\end{array}$}} & \multirow{3}{*}{$\begin{array}{c}\mathrm{X} 2 \\
\mathrm{P}- \\
\text { walus }\end{array}$} & \multicolumn{4}{|c|}{$\begin{array}{l}\text { Motfied Finden } \\
\text { wowd zwarment } \\
\text { sule }\end{array}$} & \multirow{2}{*}{\multicolumn{2}{|c|}{$\begin{array}{c}\text { Total } \\
(\mathrm{N}=20)\end{array}$}} & \multirow{3}{*}{$\begin{array}{c}\mathrm{x} \\
\mathrm{P}- \\
\mathrm{waln} t\end{array}$} & \multicolumn{4}{|c|}{ 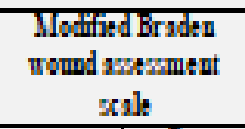 } & \multirow{2}{*}{\multicolumn{2}{|c|}{$\begin{array}{c}\text { Totsl } \\
\mathrm{N}=107)\end{array}$}} & \multirow{3}{*}{$\underset{\text { P-wht }}{\mathrm{X} 2}$} \\
\hline & \multicolumn{2}{|c|}{$\begin{array}{l}\text { Hestlby } \\
(\mathrm{N}=1 \mathrm{~W})\end{array}$} & \multicolumn{2}{|c|}{$\begin{array}{c}\text { Porr } \\
\text { benling } \\
(\mathrm{N}=y)\end{array}$} & & & & \multicolumn{2}{|c|}{$\begin{array}{l}\text { Hesltby } \\
(\mathrm{N}=155)\end{array}$} & \multicolumn{2}{|c|}{$\begin{array}{l}\text { Poor } \\
\text { buling } \\
(\mathrm{N}=12)\end{array}$} & & & & \multicolumn{2}{|c|}{$\begin{array}{l}\text { Heltity } \\
(\mathrm{N}=152)\end{array}$} & \multicolumn{2}{|c|}{$\begin{array}{c}\text { Porr } \\
\text { beding } \\
(\mathrm{N}=25)\end{array}$} & & & \\
\hline & No & $\%$ & $\begin{array}{l}\mathrm{N} \\
\mathrm{a}\end{array}$ & 4 & \begin{tabular}{l|} 
\\
$a$ \\
\end{tabular} & 4 & & $\begin{array}{l}\mathrm{N} \\
\mathrm{a} \\
\end{array}$ & $h$ & $\begin{array}{l}N \\
a\end{array}$ & 4 & \begin{tabular}{l|} 
\\
$a$ \\
\end{tabular} & $\%$ & & $\begin{array}{l}X \\
a \\
\end{array}$ & 4 & $\begin{array}{l}\mathrm{N} \\
\mathrm{a}\end{array}$ & 4 & $\begin{array}{l}\mathrm{N} \\
\mathrm{a}\end{array}$ & 4 & \\
\hline Afs(Tors) & & & & & & & & & & & & & & & & & & & & & \\
\hline Les than 00 & 71 & 67 & 8 & \begin{tabular}{l|} 
\\
3 \\
3 \\
3
\end{tabular} & $\begin{array}{l}13 \\
4\end{array}$ & $\begin{array}{l}7 \\
4 \\
4\end{array}$ & $\begin{array}{l}x_{2} \\
(22 \pi)\end{array}$ & $\begin{array}{l}1 \\
3 \\
2\end{array}$ & $\begin{array}{l}67 \\
7\end{array}$ & 7 & $\begin{array}{l} \\
8 \\
3\end{array}$ & 13 & $\begin{array}{l}b \\
7 \\
1\end{array}$ & $\mathrm{X}_{2}$ & $\begin{array}{l}13 \\
7\end{array}$ & $\begin{array}{l}73 \\
3\end{array}$ & 18 & 7 & 3 & $\begin{array}{l}7 \\
4 . \\
9\end{array}$ & $x 2(2 i 2)$ \\
\hline More than 90 & 37 & 34 & 16 & \begin{tabular}{l|}
1 \\
6 \\
2
\end{tabular} & 3 & $\begin{array}{l}7 \\
2 \\
3 \\
6\end{array}$ & P & $\begin{array}{c}2 \\
6 \\
5\end{array}$ & $\begin{array}{l}32 \\
3\end{array}$ & 3 & $\begin{array}{l} \\
\\
i \\
7\end{array}$ & 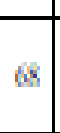 & $\begin{array}{l}1 \\
2 \\
9\end{array}$ & $\begin{array}{l}\text { P. } \\
\text { a. }\end{array}$ & 45 & $\begin{array}{l}24 \\
7\end{array}$ & 7 & 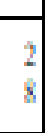 & 12 & $\begin{array}{l}2 \\
2 \\
1 \\
1\end{array}$ & pots \\
\hline $\sin$ & & & & & & & & & & & & & & & & & & & & & \\
\hline Malk & 74 & 60 & $\pi$ & $\begin{array}{l}7 \\
2 \\
7\end{array}$ & $\begin{array}{l}14 \\
6\end{array}$ & $\begin{array}{l}7 \\
0 \\
3\end{array}$ & $x_{2}$ & $\begin{array}{l}1 \\
3 \\
0 \\
0\end{array}$ & $\frac{a}{7}$ & 8 & $\begin{array}{l}b \\
6 \\
7\end{array}$ & $\begin{array}{l}13 \\
8\end{array}$ & $\begin{array}{l}6 \\
6 \\
7\end{array}$ & $x_{2}$ & $\begin{array}{l}12 \\
7\end{array}$ & $\begin{array}{l}6 \\
3\end{array}$ & 16 & $\begin{array}{l}6 \\
4\end{array}$ & $\begin{array}{l}14 \\
3\end{array}$ & $\begin{array}{l} \\
9 \\
1\end{array}$ & $x+120$ \\
\hline Female & 34 & 315 & 27 & \begin{tabular}{l|}
2 \\
7 \\
3 \\
\end{tabular} & 61 & $\begin{array}{l}2 \\
9 \\
3 \\
\end{array}$ & $\begin{array}{l}(2 \%) \\
\text { pose }\end{array}$ & 6 & $\frac{34}{3}$ & 4 & $\begin{array}{l} \\
3 \\
3 \\
3\end{array}$ & 91 & \begin{tabular}{l|} 
\\
3 \\
5 \\
5
\end{tabular} & $\begin{array}{l}\mathrm{P} \\
061\end{array}$ & 3 & $\begin{array}{l}30 \\
2\end{array}$ & 9 & 3 & 64 & $\begin{array}{l}3 \\
\vdots \\
9\end{array}$ & Poss \\
\hline Etacation & & & & & & & & & & & & & & & & & & & & & \\
\hline Illikenate & 43 & 398 & 43 & $\begin{array}{l}4 \\
3 \\
3 \\
\end{array}$ & $\mathrm{~s}$ & $\begin{array}{l}4 \\
2 \\
3 \\
\end{array}$ & & 6 & 34. & 4 & $\begin{array}{l} \\
3 \\
3 \\
3 \\
\end{array}$ & $\mathrm{~s}$ & $\begin{array}{l}4 \\
2 \\
3 \\
\end{array}$ & & 15 & $\begin{array}{l}3 \\
2\end{array}$ & 9 & $\begin{array}{l}3 \\
6\end{array}$ & 8 & $\begin{array}{l}4 \\
i . \\
i\end{array}$ & \\
\hline Read and writh & 42 & 3.9 & 31 & $\begin{array}{l}3 \\
1 . \\
3\end{array}$ & 73 & $\begin{array}{l}3 \\
3 \\
3\end{array}$ & $x_{2}$ & $\begin{array}{l}3 \\
4\end{array}$ & $\begin{array}{l}43 . \\
i\end{array}$ & 3 & $\begin{array}{l}4 \\
1 . \\
7\end{array}$ & 73 & $\begin{array}{l}3 \\
3 \\
3\end{array}$ & $x_{2}$ & 2 & $\begin{array}{l}34 \\
11\end{array}$ & 10 & $\begin{array}{l}4 \\
0\end{array}$ & $\pi$ & $\begin{array}{l}3 \\
4 . \\
5\end{array}$ & $x 2(219)$ \\
\hline Phinary & 13 & 12 & 13 & $\begin{array}{l}1 \\
3 \\
1\end{array}$ & $x$ & $\begin{array}{l}1 \\
2 \\
6\end{array}$ & Pos & $\begin{array}{l}2 \\
3\end{array}$ & $\frac{i i_{-}}{s}$ & 3 & $\begin{array}{l}2 \\
3\end{array}$ & $\mathrm{~W}$ & $\begin{array}{l}1 \\
2 \\
6\end{array}$ & $\begin{array}{l}\mathrm{P} \\
099\end{array}$ & 2 & $\begin{array}{l}13 \\
7\end{array}$ & 3 & $\frac{2}{0}$ & 30 & $\begin{array}{l}1 \\
4 \\
3\end{array}$ & pos \\
\hline Phepanawy & 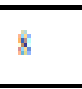 & 74 & 8 & $\begin{array}{l}3 \\
\text { i } \\
\end{array}$ & 16 & $\begin{array}{l}7 \\
7 \\
\end{array}$ & & $\begin{array}{ll}1 \\
6 \\
\end{array}$ & 82 & 0 & 0 & 16 & $\begin{array}{l}7 \\
7 \\
\end{array}$ & & 7 & \begin{tabular}{l|}
41 \\
3 \\
\end{tabular} & i & 4 & 16 & $\begin{array}{l}7 . \\
7 \\
\end{array}$ & \\
\hline Meray & 2 & 1.9 & 2 & 2 & 4 & i. & & 4 & $2 i$ & 0 & ة & 4 & $i_{1}$ & & 4 & $\begin{array}{l}2 \\
2\end{array}$ & 0 & 0 & 4 & 9. & \\
\hline Ocenpution & & & & & & & & & & & & & & & & & & & & & \\
\hline Working & 6 & 69 & $t 7$ & $\begin{array}{l}67 \\
7\end{array}$ & 13 & $\frac{6}{7}$ & $x_{2}$ & $\begin{array}{l}1 \\
3 \\
2 \\
2\end{array}$ & $\frac{67 .}{7}$ & 4 & $\begin{array}{l}3 \\
3 \\
3 \\
3\end{array}$ & $\begin{array}{l}13 \\
6\end{array}$ & $\begin{array}{l}b \\
5 \\
7\end{array}$ & $\frac{x_{2}}{(127)}$ & $\frac{12}{6}$ & $\begin{array}{l}9 \\
2\end{array}$ & 14 & b & $\begin{array}{l}14 \\
0\end{array}$ & 6 & $x(2 i s)$ \\
\hline Non-morking & 39 & $36 i$ & $\$ 2$ & $\begin{array}{l}32 \\
3\end{array}$ & $7 i$ & $\begin{array}{l}4 \\
3\end{array}$ & pos & $\begin{array}{l}6 \\
5 \\
3\end{array}$ & $\begin{array}{l}32 \\
3\end{array}$ & 8 & $\begin{array}{l}\frac{6}{6} \\
6 \\
7\end{array}$ & $7 i$ & $\begin{array}{l}3 \\
4 \\
4\end{array}$ & $\begin{array}{l}\mu_{00} \\
2\end{array}$ & 5 & $\begin{array}{l}40 \\
3\end{array}$ & iil & $\begin{array}{l}4 \\
4\end{array}$ & $6 ?$ & $\begin{array}{l}3 \\
4\end{array}$ & Pils \\
\hline Place of resident: & & & & & & & & & & & & & & & & & & & & & \\
\hline Raral & 6 & 49 & $b$ & $\begin{array}{l}67 \\
7\end{array}$ & $\frac{13}{6}$ & 6 & $x_{2}$ & 3 & $\frac{\text { 重 }}{8}$ & 14 & 3 & $\begin{array}{l}14 \\
0\end{array}$ & $\begin{array}{l}\frac{6}{6} \\
7 \\
6\end{array}$ & $x_{2}$ & 3 & $\begin{array}{l}30 \\
3\end{array}$ & 14 & b & $\begin{array}{l}14 \\
0\end{array}$ & $\begin{array}{l}67 \\
6\end{array}$ & $x(201)$ \\
\hline Lirban & 39 & $36 i$ & \pm & 3 & $7 i$ & $\begin{array}{l}4 \\
3\end{array}$ & P.635 & $\begin{array}{l}1 \\
2 \\
6\end{array}$ & $\begin{array}{l}9 \\
2\end{array}$ & ii & $\begin{array}{l}4 \\
4\end{array}$ & at & $\begin{array}{l}3 \\
2 \\
4\end{array}$ & Palls & $\frac{12}{6}$ & $\begin{array}{l}9 \\
2\end{array}$ & iil & $\begin{array}{l}4 \\
4\end{array}$ & $6 ?$ & $\begin{array}{l}3 \\
4\end{array}$ & PLis \\
\hline
\end{tabular}




\section{DISCUSSION}

Nurses are considered the "heart and soul" of every hospital. Nurses' practice play a significant role to controlwound infections, which ultimately enhances the quality of patients' care (Paudyal et al., 2015).

The current study was conducted with the aim of evaluating the effect of a wound care protocol on nurses' knowledge, practice and patients' wound healing. We showed the effectiveness of wound care protocol in wound healing of post-surgical operations in patients who were admitted in two hospitals, Mansoura University and emergency hospitals. All aspects of skin and soft tissue wounds, including acute surgical wounds, pressure ulcers and all forms of wounds, were encompassed in the specialty of tissue viability.

The present study indicates that the females nurses were more prevalent than male, concerning to their age, less than half of them their age ranged from 20 to 25 and from 30 to 35 years old in Mansoura university hospital but in the emergency hospital, the nurse's age ranged from 30 to 40 years old. Concerning years of experience, more than half of studied nurses have 10 years and more in both hospitals. however years of experience at surgery unit, less than half of them were more than five years in Mansoura university hospital and in Emergency hospital less than half of studied nurses have 5 to less than 10 years' experience. Additionally, more than half of nurses included in the present study have a diploma in nursing, except some of the nurses have a technical nursing institution. Otherwise, all nurses in the present study were married The present study revealed that more than half of the studied nurses before the protocol had unsatisfactory knowledge regarding wound care; this might have been related to the nurses' lack of training, However, nurses' knowledge became satisfactory post the protocol regarding wound care implementation, and during follow-up.

These results reflect the defects of wound care practice, especially while using the aseptic technique for wound cleaning and in items related to hand washing and compliance with protective measures during surgical or traumatic wound dressing. These findings agreed with (Ulrich et al. 2013), who reported that most nurses' performance was unsatisfactory regarding wound dressing, and has added that the reasons for the inadequate performance could be due to the lack of knowledge and skills 'training. Regarding wound care, the results of the present study showed that most of the nurses had an unsatisfactory practice regarding the dressing technique in Mansoura university 
hospital, but in the emergency hospital, more than half the study sample had satisfactory knowledge pre-protocol implementation.These percentages increased after implementing the protocol and during follow-up, where most of the studied nurses showed satisfactory practice.

Moreover, the results of the present study showed that most of the nurses had unsatisfactory practice regarding wound care pre-protocol implementation. This goes in the same line with (Yra and Walsh , 2016), who revealed that the declining nurses' practice could be due to the lack of knowledge about the importance of infection control measures during dressing, like hand washing before/after dressing and wearing a sterile glove before dressing. On the other hand, these results improved post-protocol implementation.

Additionally, the present study indicated that nursing care during wound dressing technique and using practice checklist was unsatisfactory before implementing the protocol, but has improved after protocol implementation and during follow-up after three months. This goes in the same line with (Kavaler and Spiegel, 2015); Potter and Perry, 2016). (Hollowly, 2016), emphasized that nurses must assess the wound dressing for amount, consistency, and colour of drainage. The present study revealed that the studied nurses had highly satisfactory significant improvement in practice immediately after the protocol implementation and in follow-up compared to pre-protocol implementation regarding wound assessment and observation.

In this respect, (Delaune et al. 2015) stated that hand washing was undoubtedly the most important issue in the prevention of wound infection. In the current study, immediately post-protocol implementation, most of the nurses knew how to wash hands carefully and reported the importance of hand washing to prevent wound sepsis.

In the present study, only less than half of the nurses used clean gloves when cleaning the wound, and only the lowest percent of nurses cleaned the wound from the less contaminated area to the most contaminated one. These findings demonstrated poor wound dressing practice.

The study sample in the present study also demonstrated poor documentation after wound assessment and dressing, as none of the nurses documented the time and data after wound assessment. In addition, only less than a quarter of the studied nurses took the time to instruct the patients not to touch the wound after the dressing. 
These results could be attributed to the routine dressing techniques that nurses were using e.g., dry to dry dressing.

These findings were justified by (Anthony, 2016), who found that the wet-to-dry dressing was more effective than dry-to-dry one, also (Burk, 2015), emphasized that the primary objective of wound management was the prevention of infection and to promote wound healing. In order to achieve this, the nurse should provide proper wound care using dressing techniques. Inappropriate wound management could cause more tissue damage or delay healing.

In general, the results of the present study revealed that most of the nurses working in surgical units in both hospitals had unsatisfactory practice related to all items of dressing technique, especially hand washing, using aseptic technique during cleaning wounds, cleaning equipment, and compliance with protective barriers e.g. gloves and face masks, during dressing.

These findings may have been due to the nurses' underestimation of the importance of infection control during dressing, and lack of their knowledge and practice, as none of them had any courses or in-service trainings related to infection control or wound care. These findings were similar to that of (Lynch et al. 2016).

These findings also go in the same line with the study of (Gaynes and Horan, 2012), who reported the lack of nurses' awareness about aseptic techniques; despite the availability of a large number of relevant and well-established research findings and guidelines. Also, it is important for the nurses to continuously attend seminars and conferences, regarding the best practices are disseminated.

The present study involved 207 with closed ones. All patients were admitted to the selected units in the study settings (Mansoura University and emergency hospitals). Regarding the socio-demographic characteristics of the studied patients with closed wounds, this study revealed that more than half of the studied patients pre-program were less than 50 years old, and the percent increased slightly in immediate post-program patients, and post follow-up patient in the same age. Regarding gender, most of them were males in pre-program, immediate post-program and in follow-up. These findings were consistent with those of Anthony et al. (2013); Amer et al. (2015).Also, this study showed that most of the closed-wound patients were less than 50 years old in preprogram, while in the immediate post and in follow-up, increased in the same range of age and this result not agree. These findings disagreed with those of Pachowsky et al. 
(2015), who reported that wound infection and increased age may impair wound healing. Also, the study findings contradicted with what was found by Dawodu (2014), who mentioned that closed-wounds were more common in males.

The current study findings were in accordance with those of Tooth et al. (2013), who stated that the majority of the patients were illiterate. On the other hand, these results were inconsistent with those of Furlan and Fehling's, (2016), who stated that the majority of the patients came from the rural areas

The patient's age affects a number of elements in wound healing, notably the rate of multiplication of cells and the rate of production of various cellular substances (Chvapil et al., 2015). Both tensile strength and wound closure rates decrease with age. As the individual gets older, the phases of healing become protracted so that events begin later, proceed more slowly, and often do not reach the same levels (Levenson et al., 2016).

The present study indicated that the highest percentage of wound degeneration in the studied closed-wounds patients before protocol implementation was found in patients less than 50 years old, while after immediate and follow-upprotocol implementation, this percentage was the highest in wound regeneration. This result agreed with Demographic and Health Survey (2015), who reported that increased incidence of wound degeneration may have been related to old age and decreased immune system.

Furthermore, the majority of the patients in the present study pre- and postprogram, and during follow-up could read and write. This was consistent with Lite et al., (2015), who found that less than half the patients could read and write

In the present study, the majority of patients had wound degeneration preprotocol implementation, while after implementing the protocol and during follow-up, the majority had wound regeneration. These results were in agreement with those of Caldwell, (2015), who stated that the majority of the studied patients had wound degeneration before implementing the protocol. Similarly, these findings were in agreement with those of Haiduven, (2015), who revealed that approximately one million individuals had post-operative wound degeneration.

Wounds are a burden medically and economically to both the healthcare system and to the patient (Harding et al., 2014). Due to the high cost of training and the low number of patients living in rural areas with wounds, it is not economically feasible for healthcare facilities to send staff to receive formal wound care training. This leads to a 
disparity in wound management between urban and rural areas. Lack of trained wound care providers makes evidence-based wound care difficult in rural areas (Zulkowsk, 2015).

The present study results showed that most of the studied closed-wound patients had wound regeneration pre- and post-program and during follow up. Several studies support the idea that the percentage of wound area reduction is an important indication for differentiating between healing and non-healing wounds (Flanaga, 2013).

Finally, this study was relevant to develop a protocol of wound care and measure its effect on patients' wound healing after implementing the protocol. In this respect Hall and Hall, (2012) reported the prevention of infection through modification of wound care protocol; continuous infection control and universal precautions protocol to increase the level of knowledge and practice of nurses.

\section{CONCLUSION:}

Based on the results of the current study, it can be concluded that; nurses attending the designed educational protocol. Regarding wound care showed improved levels of practice. This was manifested by improvement in patients' wound healing. Therefore, the implementations of an educational protocol.for nurses about wound care has positive effects on wound regeneration.

\section{RECOMMENDATIONS:}

Given the most important study findings, the following recommendations are suggested.

\section{For nurses}

$>$ Nurses' practice about surgical closed wound care, and infection control in general, needs to be updated through in-service training protocol..

$>$ Several educational components should be combined into concise, efficient, and effective recommendations that could be easily understood and remembered.

Further development and research is conducted to test the clinical protocols and monitor patients wound care, staff utilisation, service provision, clinical outcomes and patients satisfaction of the wound care in nursing role in the acute care setting. 


\section{REFERENCES:}

Amer A.M., Amin, S.Z., Farid, S., (2015). The Egyptian Fertility Survey. 4 vols. Cairo: Central Agency for Public Mobilization and Statistics

Anderson I. (2014). Debridement methods in wound care. Nursing Standard; 20:65-72.

Andrews and Boyle.(2014) Antibiotic Use after Cefuroxime Prophylaxis in Surgery. Clin PharmacologicalTherapy; 50(2): pp215-220

Anthony, W.T. (2016). Physiology of the acute wound. Clin Plas Surg; 25(3): PP 321340.

Anthony, W.T., Burns N. G., Rove S. (2013). The practice of nursing research: Conduct, Critique, and Utilization5th edition. Elsevier: Saunders.

Australian Medicines Handbook (Internet) (2015). Monitoring pressure ulcer healing in persons with disabilities. Rehabil Nurs; 30(3):pp92-98.

Baranoski S., Ayello E. (2015).Wound care essentials: Practice principles. Lippincott Williams \& Wilkins Philadelphia.PP21-29

Bates-Jensen BM. (2011).The pressure sore status tool: a few thousand assessments later. Adv Wound Care.73-

Braden B., Bergstrom N. (2015). Braden Wound Assessment Scale and A conceptual schema for the study of the etiology of pressure sores. Rehab Nurs; 12:8-1

Burk L.A.(2015).Aging and wound healing. World journal of surgery, 28(3), PP 321326.,

Caldwell, M.T. (2015). Wound healing. In: Aston SJ, Besley RW, Thorn CH, editors. Grabb and Smith's plastic surgery. fifth edition. Philadelphia: Lippincott-Raven; p. 3.

Canadian Association of Wound Care (2014): Evaluation of Blunt Suture Needles in Preventing Percutaneous Injuries Among Health-Care Workers during Gynecologic Surgical Procedures, New York City, March 2014-June 2013. MMWR Morb Mortal Wkly Rep; 46(2): 25-9.

Carpenito, A. (2015). Factors Influencing Wound Healing after Surgery for Metastatic Disease of the Spine. Spine; 23:pp 726-633. 
Chou \& Conifer (2012). Post surgical Infections Associated with Nonsterile Implantable Devices. MMWR Morb Mortal Wkly Rep; pp 41(15): 263

Chvapil T., Elsayed, S., Gupta, S., Mendonca, A. D., Tayton, K. J. J. (2015). Choice of dressing has a major impact on blistering and healing outcomes in orthopedic patients. Journal of Wound Care, 14(1), pp27-29.

Dawodu C. (2014). Topical vitamins. J Drugs Dermatol 7(7 Suppl):s2-s6 [PubMed]

Delaune G., 2nd, Janis J.E., Attinger C.E. (2015). The basic science of wound healing (retraction of Witte M., Barbul A. In: Surg Clin North Am; 77:509-528). Plast Reconstr Surg 117 (7 Suppl):PP12S-34S[PubMed).

Demographic and Health Survey (2015). Calverton, Maryland: Ministry of Health and Population [Arab Republic of Egypt], El-Zanaty and Associates, and Macro International.

Dolly J. (2013). Nutrition management of pressure ulcers. Nutr Clin Pract; 25:50-60- Pub Med . HTTP://www.PubMed.com

Eastes (2015) Wound healing: General principles of wound healing. Surg Clin N Am; 77:pp509-28

Falanga M.S. (2013): Wound Infection Rates in Clean Surgery: A Potentially Misleading Risk Classification. Infect Control Hosp Epidemiol; 13(8): 457-62.

Furlan K.A., Fehling's D.J. (2016). Effects of acute ethanol exposure on the early inflammatory response after excisional injury. Alcohol Clin Exp Res 31:317323[PubMed]

Gaynes R.P., Horan T.C. (2012): Surveillance of Nosocomial Infections. In: Mayhall C.G. (Ed.): Hospital Epidemiology and Infection Control. Baltimore: Williams \& Wilkins; pp. 1017-1031.

Haiduven L.A. (2015). Aging and wound healing. World journal of surgery, 28(3), 321- 326. 
Hall M.D., Hall C., Bates-Jensen B., Parslow N., Raizman R., Singh M., Ketchen R. (2012). Bates-Jensen Wound AssessmentTool: pictorial guide validation project. J Wound Ostomy:pp 35-45

Harding W.D., Morris, Patel, (2014). Pressure ulcer scale for healing: derivation and validation of the PUSH tool. The PUSH Task Force. Adv Wound Care 1997; 10(5):PP96-101.

Hollowly H. (2016). Benefits of an oral nutritional supplement on pressure ulcer healing in long-term care residents. J Wound Care 17:PP 476- 480 [PubMed]

Johnny W.T., Talbot T.L., Norton J.A. (2014). Preoperative or postoperative doxorubicin hydrochloride (Adriamycin): which is better for wound healing? Surgery 100:9-13 [Pub Med],

Kavaler, J., Spiegel, B. (2015). Essential Medical Statistics. Second edition. Massachusetts: Blackwell Science.PP 33-37

Levenson L., Schwartz-Arad D. (2016). The effect of cigarette smoking on dental implants and related surgery. Implant Dent pp14:357-361 [PubMed].

Lippincott (2015) A prospective evaluation of emergency department bedside ultrasonography for the detectionof acute cholecystitis. Ann Emerg Med. 2010;pp 115121.

Lit A.P., Webster A., Gruneberg R.N., Treasure T., Sturridge M.F. (2015). Repeatability of the asepsis wound scoring method. Lancet; 24(1) (8491):1208-9.

Pachowsky M., Gould, Lisa et al. (2015). 'Chronic Wound Repair And Healing In Older Adults: Current Status And Future Research'. Wound Repair and Regeneration. Pp 23.1: 1-13.

Paudyal T.M., Golub J.E. (2015): New Approaches to Reduce Staphylococcus Aureus Nosocomial Infection Rates: Treating S. Aureus Nasal Carriage. Ann Pharmacother; 32: PP7-16. 
Robson N., Sorrell J., Bielby A., Searle R. (2016). A survey of postoperative wound dressing practice before and after implementing national guidelines. Clinical Research. Wound UK; 7, (4): 12-22.

Rodriguez P. G., Felix, F. N., Woodley, D. T., Shim, E.K. (2015). The role of oxygen in wound healing: a review of the literature. Dermatologic surgery: official publication for American Society for Dermatologic Surgery [et al.], 34(9), 1159-1169.

Sussman C. Bates-Jensen B. (2016). Tools to measure wound healing. In Sussman C, Bates-Jensen B, editors. Wound Care, a Collaborative Practice Manual for Health Professionals, 4 ed. Baltimore (US); P. 131-72

Tooth A., Mckenna D.M., Geraghty L.H. (2013). The Effects of Diabetes Mellitus on Wound Healing. Plast Surg Nurs; 11(1): pp20-25.

TaylorA.J., Reichner J.S., Albina J.E. (2016), Macrophage-induced neutrophil apoptosis. J Immunol165:PP 435-441 [PubMed]

Ulrich M.A, Guo, S., DiPietro, L.A. (2013). Factors Affecting Wound Healing. Journal of Dental Research. 89: PP 219-229.

Wilson J.A. (2014). toward an intelligent wound assessment system. Ostomy Wound Manage; 41(7A Suppl.): S80-S6; discussionS7.pp 77

Yra, P.E., Walsh M.G. (2016). Development, validity, reliability, and responsiveness of a new leg ulcer measurement tool. Adv Skin Wound Care; 17(4 Pt.1):PP 187-196.

Zulkowsk (2015). The impact of warming on pain and wound healing after hernia surgery: a preliminary study. J Wound Care 2006;15(3):pp104-8.

Zumbudio K.J., Furnary A.P., Grunkemeier G.L., Bookin S., Kanhere V., Starr A. (2014). Glucose Control Lowers the Risk of Wound Infection in Diabetics after Open Heart Operations. Ann ThoracicSurge; 63(2): 356-61. 
تأثير برتوكول الـنايـة بـالـرورح على مـــارسات المــرضين و التأم جـروح المـرضى

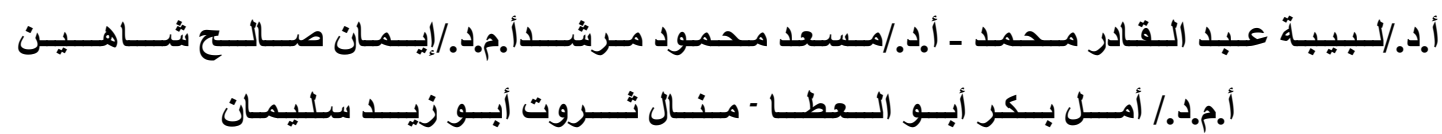

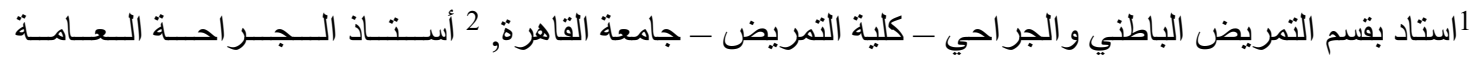

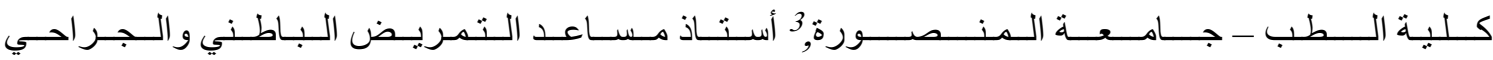

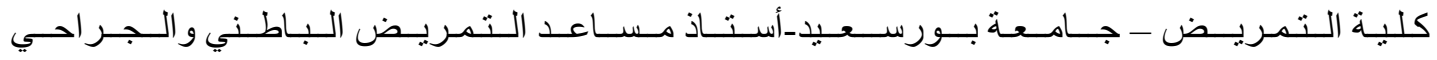

كليـة الـتـــريــض - جـامـعـة بــورســــيد-(ماجستير تمريض باطني وجر احي - جامعة عين شمس، 2007)

\section{الخلاصة}

تعتبر عدوى الجروح بعد العمليات من أكثر العوامل تأثيرا على صحة مريض الجراحة ويظهر تأثيرها على أنى

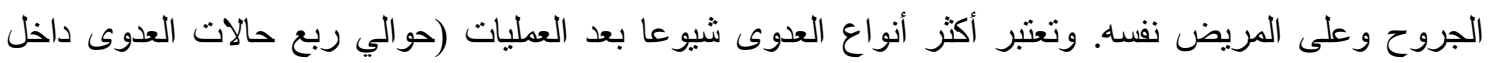

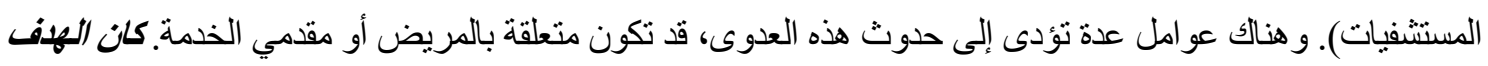

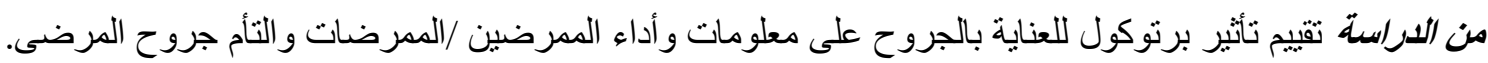
تم استخدام تصميم شبه تجريبي لتنفيذ هذه الدراسة. نم أجراء الدراسة في وحدات الجراحة العامة في مستشفى جامعة المنصورة ومستشفي الطوارئ. اشتملت عينة الدراسة علي عدد (50) ممرضة وعدد (207) مريض بالغ مصابين بجروح مفتوحة. تم إعطاء طاقم التمريض برنامج نعليمي تمريضي مكون من ثلاث مر احل لتنفيذ برونوكول العناية

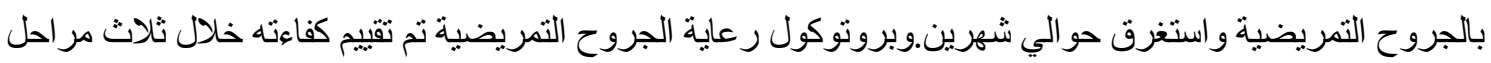
(قبل البرنامج، بعده، ومتابعة بعد 12 أسبوع). أظهرت نتائج الدراسة تحسنا معنويا بين أفراد الدراسة في حالة التهرئ التئام الجروح من حيث عدوى الجروح المنخفضة وتحسين مستوى الرضا عن مستوى الرعاية المقدمة وساهم البروتوكول بالدراسة الحالية في تخفيض المضاعفات الثانوية.نتائج هذه الدراسة تدعم فرضيات البحث و و أظهرت نتائج أفضل اللمريض أثناء البرنامج و عند المتابعة بالمقارنة مع حاله المرضى قبل البرنامج. 